\title{
A POLÍTICA EXTERNA DO GOVERNO LULA PARA A AGENDA AMBIENTAL: UMA ANÁLISE À LUZ DE TEORIAS DE PROCESSO DECISÓRIO'
}

\author{
LULA'S ADMINISTRATION FOREIGN POLICY FOR THE ENVIRONMENTAL \\ AGENDA: AN ANALYSIS FROM THE THEORIES OF DECISION-MAKING
}

DOI: 10.5380/cg.v9i2.76367

Victor de Matos Nascimento

\begin{abstract}
Resumo
O governo Lula (2003-2011) se iniciou no começo do século XXI, período onde o multilateralismo se ampliava. O governo brasileiro, ciente das possibilidades que este arranjo da ordem mundial oferecia, seguia intensificando sua presença em fóruns multilaterais. Nesse sentido, o meio ambiente se apresentou como uma das principais agendas da política externa do país à época. Este artigo analisa esse período à luz de teorias de processo decisório, articulando empiria e reflexões teóricas para compreender o papel da relação entre as dimensões doméstica e internacional na composição da política externa voltada para a agenda ambiental. É feito um estudo de caso da atuação brasileira na COP 15, uma das principais arenas nesse contexto. Como será demonstrado, as pressões advindas da dimensão doméstica, tendo em vista a multiplicidade de agentes e interesses, foram decisivas para a composição da política externa ambiental, bem como a ordem multilateral e o protagonismo do presidente Lula.
\end{abstract}

Palavras-Chave: Política externa; Meio ambiente; Processo decisório; Multilateralismo.

\begin{abstract}
Lula' administration (2003-2011) started at the beginning of the 21st century, a period when multilateralism was expanding. The Brazilian government, aware of the possibilities that this arrangement of the world order offered, continued to intensify its presence in multilateral arenas. In this sense, the environment presented itself as one of the main county's foreign policy agendas at the time. This article proposes to analyze this period from the theories of decision-making, articulating empirics and theoretical reflections to understand the role of the relationship between the domestic and international dimensions in the composition of foreign policy for the environmental agenda. A case study of the Brazilian performance at COP 15 is made, one of the main arenas in this context. As will be demonstrated, the pressures arising from the domestic dimension, in view of the multiplicity of agents and interests, were decisive for the composition of environmental foreign policy, as well as the multilateral order and the role of President Lula.
\end{abstract}

Keywords: Foreign policy; Environment; Decision-making; Multilateralism.

\section{INTRODUÇÃO}

A questão ambiental ganhou maior destaque na agenda internacional a partir da Conferência de Estocolmo realizada em 1972. Já em 1997, um outro importante passo foi dado, a

\footnotetext{
${ }^{1} \mathrm{O}$ presente trabalho foi realizado com apoio da Coordenação de Aperfeiçoamento de Pessoal de Nível Superior - Brasil (CAPES).

${ }^{2}$ Mestrando em Relações Internacionais pelo Programa de Pós-Graduação em Relações Internacionais da PUC Minas e bacharel em Relações Internacionais pela PUC Minas. E-mail: victormatosnasc@gmail.com. ORCID: https://orcid.org/0000-0002-9767-0769.
} 
assinatura do Protocolo de Quioto. Adentrando o século XXI, período onde o contexto internacional era do pós-Guerra Fria e as ideias de cooperação e de governança global ganhavam maior relevância, realizou-se em 1992, na cidade do Rio de Janeiro, a Eco-92. Foi nesta conferência que se estabeleceu a Convenção Quadro das Nações Unidas para a Mudança do Clima (UNFCCC), que somada ao Protocolo, compunham os principais instrumentos do Regime Internacional de Mudança Climática (RIMC) (MOOSMANN, et. al, 2019). Desse modo, tendo em vista as evidências que apontavam para o aumento da temperatura global, questões ambientais passaram a ser entendidas como um problema de ação coletiva que necessitava do envolvimento de todos os países para ser solucionado.

A política externa (PE) do governo de Luiz Inácio Lula da Silva (2003-2011) deu prosseguimento ao plano brasileiro que se iniciou em meados de 1990 (pós-Guerra Fria) de aumentar a participação em fóruns e organizações internacionais. Dentre as temáticas dessas participações, a ambiental se intensificou, tendo em vista as discussões em torno dos recursos naturais que o país dispunha, o aumento da produção agropecuária e da pauta exportadora, bem como a relevância da floresta amazônica para o planeta (ESTEVO, 2011).

Este artigo tem o objetivo de analisar a política externa brasileira (PEB) para a agenda ambiental do governo Lula, para compreender como sua composição foi influenciada pela interação entre as dimensões doméstica e internacional. Escolheu-se a Conferência das Partes (COP) 15 como caso a ser aprofundado, tendo em vista que esta reunião significou uma das maiores expressões da PEB nessa temática. O modelo analítico que se propõe para alcançar este objetivo tem como premissa a ideias da teoria da Escolha Racional e da Teoria dos Jogos. Assume-se, tal como apontam George Tsebelis (1998), Elinor Ostrom (2007) e Putnam (2010), que os atores estão inseridos em uma rede de jogos e de arenas. As instituições e os vínculos entre os países são fundamentais para a compreensão da atuação no ambiente externo, assim como indicam Robert Keohane e Milner (1996). Ademais, por meio dos modelos de Graham Allison (1971) será possível analisar o papel do tomador de decisão e da dimensão doméstica na concepção da política externa. Finalmente, como aponta Helen Milner (1997), destaca-se o papel da cooperação e da informação nas interações que constituem esse processo.

Metodologicamente, este artigo apresenta uma análise que articula teoria e empiria, se valendo de revisão bibliográfica e de análise documental acerca do tema, mobilizando a bibliografia mencionada, documentos e reportagens dos processos a serem analisados. A primeira seção foca na dimensão externa e em sua importância para o processo político. A segunda seção incorpora a dimensão doméstica, para evidenciar a relação de ambas na formulação da política externa. A análise da atuação brasileira na COP 15 é feita de modo articulado com o conteúdo das duas seções. Por fim, nas conclusões, é feita uma reflexão sobre os caminhos da PEB para a agenda ambiental/climática. 


\section{O PROCESSO DECISÓRIO EM POLÍTICA EXTERNA DA AGENDA AMBIENTAL DO GOVERNO LULA}

A PE do governo Lula se concentrou na avaliação das oportunidades que a ordem global multilateral oferecia. A abordagem era sobretudo voltada para os países emergentes e do Sul global. O Brasil se movimentou no sentido de indicar ao mundo a importância que tinha enquanto um ator relevante para a política internacional. Isso foi feito, por exemplo, por meio de maior participação em negociações globais e em coalizões voltadas para o Sul, como o G-203 e o BRICS4 (ESTEVO, 2011).

Tsebelis (1998) faz uma leitura da realidade que se vale da ideia de que os indivíduos orientam suas ações a partir da racionalidade. Esse pressuposto significa que os atores, sejam eles individuais ou institucionais, buscam realizar seus objetivos de modo instrumental. O autor se vale da teoria dos jogos enquanto instrumento analítico, onde os jogadores, diante das situações, dispõem de opções/estratégias, determinam juntos os resultados dos jogos e recebem os payoffs ${ }^{5}$ associados a esta dinâmica. A teoria sustenta que as regras e os payoffs são fixos, sendo assim os atores irão orientar suas escolhas para estratégias que lhes pareçam ótimas para si mesmos, e que os levem a maximizar seus resultados. Ressalta-se que estas escolhas são feitas levando em conta o que eles acreditam que os outros atores também irão fazer (TSEBELIS, 1998).

O governo brasileiro, como aponta Cervo (2008), tradicionalmente orientou sua política externa com o pragmatismo como instrumento eficaz para a defesa dos interesses do país (CERVO, 2008). Isso se manteve com a administração Lula, uma vez que a orientação para o Sul global fazia parte de uma estratégia de melhorar a imagem do país no exterior e de conferir-lhe maior relevância, sobretudo no âmbito regional. Entendendo o Brasil como um ator racional, é possível observar que o governo reconhecia o multilateralismo enquanto a regra à época, e os benefícios advindos de interações em agrupamentos, como os BRICS, eram os payoffs.

Na discussão ambiental internacional, é importante considerar o debate dentro do RIMC, e como o Brasil se posicionava nele na época. O Regime, estabelecido em 1992, é fruto de esforços diplomáticos que visavam fortalecer as bases científicas e influenciar a tomada de decisão internacional na questão climática. O Brasil, até meados da década de 1980, focou em seu desenvolvimento, aumentando a poluição e a exploração dos recursos naturais. Mas o valor de mercado dos recursos foi se deteriorando, e a tolerância internacional para a poluição também foi diminuindo. Segundo Viola (2002), a posição brasileira quando do estabelecimento do Regime possuía duas orientações:

\footnotetext{
3 Agrupamento de países composto por África do Sul, Alemanha, Arábia Saudita, Argentina, Austrália, Brasil, Canadá, China, Estados Unidos, França, Índia, Indonésia, Itália, Japão, México, Reino Unido, República da Coreia, Rússia, Turquia e União Europeia (G-20, 2020).

4 Agrupamento de países emergentes composto por Brasil, Rússia, Índia, China e África do Sul.

5 Resultado/ganho do jogo, a depender de suas escolhas e das estratégias de seu adversário (SILVEIRA; BURNQUIST, 2009).
} 
em primeiro lugar, de que os problemas ambientais globais eram relevantes e deveriam ser tratados de maneira prioritária pela comunidade internacional; em segundo, de que a responsabilidade se diferenciava tanto pela causa quanto pela solução dos problemas ambientais globais, o que aumentava o custo dos países ricos (VIOLA, 2020, p. 35).

Em meados de 2009, as preocupações do Regime estavam baseadas no Quarto Relatório de Avaliação do Painel Intergovernamental das Nações Unidas para Mudanças Climáticas (IPCC) publicado em 2007, que versava sobre os impactos da mudança do clima, a vulnerabilidade dos países e os caminhos para medidas de adaptação (UNFCCC, 2009). Desse modo, a orientação da PEB, desde a ECO-92, se manteve em torno do princípio das responsabilidades comuns, porém

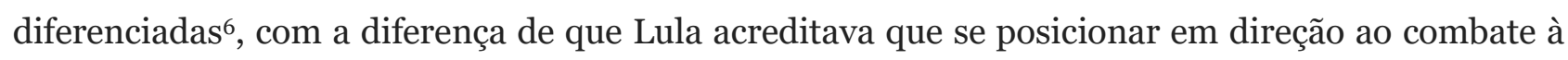
mudança do clima poderia ser politicamente interessante para o Brasil.

Segundo Ostrom (2007), uma arena é composta por uma situação e pelos atores nela inserida. O ator pode ser corporativo ou individual, tal como concebe Tsebelis (1998). A arena é a unidade conceitual onde a análise poderá ser feita e tal observação deve levar em conta o contexto institucional em que ela se insere. Ademais, a arena é um espaço social onde os atores interagem, trocam informações, bens, e podem dominar uns aos outros. A autora aponta para sete grupos de variáveis: “(1) participantes, (2) posições, (3) resultados, (4) linkages dos resultados das ações, (5) o controle que os participantes exercem, (6) informação, e (7) os custos e benefícios associados aos resultados" (OSTROM, 2007, p. 28, versão livre do autor7).

Aprofundando na agenda ambiental do governo Lula, exemplos de arenas são questões domésticas como a da Amazônia e os fóruns multilaterais onde o governo atuou. Em 2009 aconteceu em Copenhague, na Dinamarca, a COP 15. A ocasião foi marcada por um importante discurso proferido pelo presidente Lula, que assim como outros 114 líderes mundiais e cerca de 40.00o representantes de governos, Organizações Não-Governamentais (ONG) e da mídia, compunha os participantes da arena em questão. O principal objetivo da reunião era estabelecer metas de redução de Gases de Efeito Estufa (GEE) e a posição do governo brasileiro era favorável a tais metas, mas respeitando o princípio das responsabilidades comuns, porém diferenciadas (LEIA, 2009).

Na conferência, Lula reconheceu a necessidade que os países têm de tomar medidas para combater o aquecimento global. Seu discurso foi aberto com a seguinte declaração: "confesso a

\footnotetext{
${ }^{6}$ Princípio número sete da Declaração do Rio sobre o Meio Ambiente (1992): "os Estados devem cooperar, em um espírito de parceria global, para a conservação, proteção e restauração da saúde e da integridade do ecossistema terrestre. Considerando as distintas contribuições para a degradação ambiental global, os Estados têm responsabilidades comuns, porém diferenciadas. Os países desenvolvidos reconhecem a responsabilidade que têm na busca internacional do Desenvolvimento Sustentável, em vista das pressões exercidas por suas sociedades sobre o meio ambiente global e das tecnologias e recursos financeiros que controlam" (ONU, 1992, s/p).

7 Texto original: "(1) participants, (2) positions, (3) outcomes, (4) action-outcome linkages, (5) the control that participants exercise, (6) information, and (7) the costs and benefits assigned to outcomes."
} 
todos vocês que estou um pouco frustrado. Porque há muito tempo discutimos a questão do clima e cada vez mais constatamos que o problema é mais grave do que nós possamos imaginar" (LEIA, $2009, \mathrm{~s} / \mathrm{p})$. No entanto, tendo em vista a posição dos outros atores na arena, o controle que países desenvolvidos exerciam sobre as decisões e os custos e benefícios associados ao que fosse assinado, Lula defendia o seguinte: "nós passamos um século sem crescer, enquanto outros cresciam muito. Agora que nós começamos a crescer, não é justo que voltemos a fazer sacrifício” (LEIA, 2009, s/p).

Pelo modelo proposto por Ostrom (2007) é possível analisar mais alguns pontos da atuação política de Lula nessa arena da COP 15. A autora propõe 4 grupos de variáveis para que se analise 0 comportamento do ator:

1. os recursos que o ator traz para a situação; 2. os valores que os atores atribuem aos estados do mundo e às ações; 3. o modo como atores adquirem, processam, retêm e usam contingências de conhecimento e informação; e 4. os processos que os atores usam para selecionar cursos particulares de ação (OSTROM, 2007, p. 28, versão livre do autor ${ }^{8}$ ).

À época, o argumento central do discurso de Lula era anunciar as medidas que o governo brasileiro estava tomando em relação ao meio ambiente. Desse modo, Lula levava recursos políticos para a arena de negociação - variável 1, como o compromisso de aprimorar a matriz energética do país e de reduzir o desmatamento da Amazônia em 80\% até 20209 (LEIA, 2009). Além disso, acerca dos valores que ele atribuía aos estados do mundo - variável 2, tem-se a concepção das responsabilidades que os países desenvolvidos possuíam, e também a de que o multilateralismo seria um meio para que se alcançassem-se os objetivos brasileiros.

A variável 3 diz respeito ao modo como Lula adquiriu, processou e usou os conhecimentos para elaborar suas ações. A informação é uma variável central nessa discussão e será desenvolvida melhor a posteriori, uma vez ela envolve um diálogo constante entre grupos domésticos e o âmbito externo. Chama-se a atenção aqui para o fato de que na ocasião da COP 15, o Ministério do Meio Ambiente (MMA) teve protagonismo na concepção do posicionamento do país. "Desde as negociações no âmbito da Rio-92, a posição brasileira em mudanças climáticas era tudo informado internamente pelo Ministério da Ciência e Tecnologia, Inovações e Comunicações (MCTIC) e pelo Ministério das Relações Exteriores (MRE), contudo, com uma crescente participação do MMA" (PEREIRA, 2019, p. 88).

Já sobre os processos utilizados por Lula e por sua administração para selecionarem os cursos de ação sobre a questão climática - variável 4, tem-se novamente a orientação do governo

\footnotetext{
${ }^{8}$ Texto original: "1. the resources that an actor brings to a situation; 2. the valuation actors assign to states of the world and to actions; 3 . the way actors acquire, process, retain, and use knowledge contingencies and information; and 4. the processes actors use for selection of particular courses of action."

92004 foi o ano com a maior taxa de desmatamento (27.772 km2). 2009, ano do discurso na COP 15, essa taxa já havia caído para pelo menos 1/3. Ela seguiu caindo até 2012 e depois voltou a subir. Tendo como referência o ano do discurso, dados de 2018 apontam que a redução não chegou a sequer 60\% até a época. Já em 2019 e em 2020 voltaram a disparar (INPE, 2018).
} 
de conferir protagonismo e relevância para o país na ordem mundial à época. Oliver Stuenkel (2018) afirma que, "considerando as perspectivas muito diversas que têm que ser levadas em conta ao tomar decisões de importância global - por exemplo, quanto à mudança climática -, uma ordem bipolar ou multipolar pode ser muito mais adequada do que uma ordem ocidentocêntrica" (STUENKEL, 2018, p. 99). Lula sabia que era necessário coerência nas áreas de projeção internacional do país, dentre elas a área ambiental. Desse modo, compromissos como o da redução do desmatamento eram vistos como o caminho rumo a uma posição de destaque em agendas que o Brasil poderia assumir protagonismo. A própria associação com países do Oriente, como China e Rússia, por meio dos BRICS, também indica essa movimentação da busca por parceiros e por esferas de influência junto a atores e a agendas alternativas à ordem ocidental do imediato pósGuerra Fria.

O resultado da COP 15 também reflete este cenário. Em 18 de dezembro de 2009, foi assinado o Acordo de Copenhague, documento que estipulava compromissos voluntários para que os países reduzissem suas emissões. Os países líderes na formulação do documento foram Brasil, China, Índia, África do Sul e os Estados Unidos (COP 15/MOP 5, 2020). Os quatro primeiros atuaram na mesma direção do discurso de Lula, reforçando o argumento comum dos países em desenvolvimento. Já um dos fatores que explicam o protagonismo estadunidense na questão era o fato de não haver ratificado o Protocolo de Quioto e de não apresentado, até então, ações robustas na direção da redução de emissões (MOOSMANN, et. al, 2019).

De todo modo, como alguns países, sobretudo alguns em desenvolvimento como Bolívia, Venezuela, Nicarágua e Cuba, não tiveram a mesma participação na formulação do documento, optaram por não aceitar o acordo, o que fez com que não tivesse caráter decisório e não fosse juridicamente vinculante (COP 15/MOP 5,2020 ). Um mês após a reunião, em janeiro de 2010, a embaixada do Brasil em Berlim transmitiu um comunicado à UNFCCC reafirmando os compromissos estipulados por Lula em seu discurso e nas negociações. O documento reforçava que o Brasil faria ações em caráter voluntário, como a redução do desmatamento da Amazônia e do Cerrado, ponto mencionado no discurso de Lula. Além disso, ampliaria a eficiência energética por meio de energias alternativas menos intensivas em emissões de $\mathrm{CO} 2$, totalizando uma redução estimada entre 36,1\% e 38,9\% até 2020 (UNFCCC, 2010a).

Entretanto, internacionalmente o desafio de vincular mais países ao acordo permanecia. Em fevereiro de 2010, a embaixada brasileira enviou um novo documento, reforçando a importância de sua participação nas negociações e o caráter multilateral do que foi acordado. No documento, o Brasil reafirmava a natureza global do desafio da mudança do clima e demandava que a UNFCCC incentivasse todos os países para que se envolvessem em uma resposta multilateral, ainda que respeitando o princípio das responsabilidades comuns, porém diferenciadas (UNFCCC, 2010b). Essa trajetória da atuação brasileira na COP 15 pode ser sintetizada, portanto, em dois pontos: houve uma articulação entre as instituições brasileiras e o presidente Lula, uma vez que 
seus discursos seguiam a mesma linha das medidas adotadas por elas; e o país se valeu de parcerias multilaterais para alavancar sua liderança na agenda ambiental.

\section{A INFLUÊNCIA DA AGENDA DOMÉSTICA SOBRE A POLÍTICA EXTERNA}

Incorporando a dimensão/arena doméstica à discussão, além do presidente Lula e de seu protagonismo, algumas figuras são importantes na questão ambiental. Marco Aurélio Garcia era secretário e intelectual do partido de Lula, o Partido dos Trabalhadores (PT), integrante relevante das decisões de política externa. Ademais, dois ministros do Meio Ambiente, que também eram ambientalistas, tiveram relevância nessa área: Marina Silva (2003-2008), natural do Acre, professora, ex-seringueira e que veio a se tornar uma liderança em nível nacional e internacional, e Carlos Minc (2008-2010), que também era professor e economista (PEREIRA, 2019).

Para Milner (1997) a política doméstica e as relações internacionais estão interrelacionadas. A autora compartilha dos frameworks da teoria da escolha racional e da teoria dos jogos, ressaltando que o interesse nacional é uma variável central nessa discussão. Além dela, outra variável também importa: a informação. Sobretudo domesticamente, a forma como a informação é compartilhada entre aqueles responsáveis pelas decisões de política externa tem a ver diretamente com sua eficiência ou ineficiência. Milner (1997) afirma que informação incompleta pode levar a vantagens políticas, mas também a resultados ineficientes (MILNER, 1997).

Domesticamente, na área ambiental, as relações entre Marina Silva e outros decisores do governo Lula foram conflituosas. Havia, dentro do governo, uma coalizão de atores políticos e econômicos, inclusive lideranças do PT, que eram contra aspirações ambientalistas da ex-ministra. O argumento dessa coalizão era de que era necessário flexibilizar barreiras e licenciamentos ambientais para promover o desenvolvimento do país, sobretudo em regiões menos avançadas, como o Norte e o Nordeste (PEREIRA, 2019). Chama-se a atenção aqui para o papel que estas disputas possuem na formatação de políticas públicas domésticas e também para a política externa. As informações vêm de fontes variadas, como ambientalistas, o próprio ministério, ou grupos focados em desenvolvimento econômico. Consequentemente, alguns dispunham de mais vantagens políticas do que outros, bem como os resultados poderiam ser sub-ótimos.

Levando em conta, portanto, as informações disponíveis, o comportamento de cada ator é uma resposta ótima ao comportamento dos outros e à estrutura institucional. Ademais, Tsebelis (1998) afirma que um jogo é um tripé composto por um conjunto de jogadores, estratégias (que dependem das informações disponíveis), e payoffs para cada um. Kageyama e Santos (2012) afirmam que, embora o governo Lula fosse tido como uma coalizão, muitas contradições foram geradas em função da necessidade de governabilidade. Marina Silva, entendida como uma jogadora nessa arena, trazia referências de seringueira no interior do Acre. Além disso, os 
produtores rurais também eram jogadores importantes, sobretudo os de menor poder político, que foram o foco do primeiro mandato de Lula. Isso ocorreu tendo em vista que cerca de $70 \%$ do alimento básico brasileiro advinha de agricultura familiar (KAGEYAMA; SANTOS, 2012).

No entanto, como a produção do ator, produtores rurais, era voltada para o setor doméstico, seu poder econômico e de barganha era limitado, perdendo para indústrias de maior porte. Consequentemente, os atores, Marina Silva e o MMA, também perdiam disputas para o Ministério da Agricultura, Pecuária e Abastecimento (MAPA). O MMA incentivava os poderes da república a adotarem medidas fortes para controle do uso comercial de produtos derivados de biotecnologia. Já o MAPA ia na contramão, tendo em vista o valor em ascensão desses produtos à época (PEREIRA, 2019).

Para compreender melhor a relação entre o internacional e o doméstico, Putnam (2010) propõe a abordagem dos "jogos de dois níveis", assumindo que estas duas dimensões estão entrelaçadas. No nível doméstico, grupos perseguem seus interesses pressionando o governo a adotar políticas que os favoreçam. No internacional, os governos buscam minimizar as consequências das questões externas e articular isso com suas capacidades de satisfazerem as pressões domésticas (PUTNAM, 2010). No caso brasileiro, o governo Lula teve que lidar com os desafios domésticos advindos de setores empresariais e produtivos, além das demandas de ONGs e movimentos sociais, e internacionalmente com questões que surgiram a medida que o protagonismo brasileiro se sobrepunha em algumas áreas, como a econômica.

Desde a origem do PT e ao longo de sua trajetória, Lula contou com o apoio de movimentos sociais urbanos, estudantis, da luta das mulheres, dos direitos humanos e ambientais. As ONGs ambientalistas tiveram um papel nunca antes visto enquanto grupo de pressão no âmbito da sociedade civil brasileira. Isso se deu em função da própria ascensão desses grupos, viabilizada pela globalização e pela ampliação da internet, mas também do espaço que o governo oferecia para a discussão ambiental. Um exemplo de espaço era o Conselho Nacional de Meio Ambiente (CONAMA), que oferecia um canal institucional para que suas vozes fossem ouvidas, ainda que, em muitos momentos houvessem desavenças (LOSEKANN, 2014).

Olhar para a dimensão econômica oferece acréscimos importantes a essa discussão. Como afirmam Keohane e Milner (1996), para compreender as políticas nacionais é necessário considerar os vínculos entre as economias nacionais e a mundial. Além disso, é também necessário considerar que elas estão em constantes mudanças, tendo em vista as oportunidades oferecidas pelo mercado. $\mathrm{O}$ argumento central é que a economia internacional impacta nas preferências políticas domésticas. No entanto, quando se trata de Estados fortes, como o exemplo da China oferecido pelos autores, esses impactos podem ser bloqueados por um tempo (KEOHANE; MILNER, 1996).

Esse argumento importa tendo em vista a relevância da agricultura na economia brasileira no governo Lula. A partir de 2003, as exportações e importações passam a apresentar um caráter ascendente. Na pauta exportadora os principais produtos eram algodão, arroz, aveia, canola, 
centeio, cevada, feijão etc. Em 2010 as exportações aumentaram em 265,42\% em relação a 2003. Chama-se a atenção para o ano de 2009 em que houve uma queda expressiva em função da crise financeira global (CAVALCANTE; LIMA, 2013).

É válido destacar, nesse momento, dois pontos: o impacto da agricultura na agenda ambiental; e o impacto da crise financeira global na economia brasileira à época. Como dito, o poder político e econômico da agricultura industrial sobre a agricultura familiar era superior tendo em vista seu objetivo final ser o mercado internacional. Historicamente, mesmo com a industrialização, o Brasil depende das commodities ${ }^{10}$ como carro chefe de sua economia. Sua produção se vale de vastos espaços de terra, frequentemente utiliza agrotóxicos e depende da utilização intensiva de água, processos altamente nocivos ao meio ambiente (KRUGMAN, 2015). Desse modo, o segundo ponto é uma consequência do primeiro, tendo em vista o pouco valor agregado das exportações brasileiras e o grau de exposição da economia a mudanças externas nas dinâmicas comerciais.

A crise de 2009 chamou a atenção de Lula para esta questão e isso se refletiu em seu discurso na COP 15. Além do olhar para o desmatamento e para a matriz energética, uma de suas propostas era de mudar o sistema da agricultura brasileira. Isso era necessário, evidentemente, em virtude da preocupação ambiental, mas, sobretudo, visando reduzir a exposição e a vulnerabilidade a oscilações da economia internacional. Além disso, levando em conta uma das principais pautas de seu governo, a redução da pobreza, Lula não pensava em abrir mão de uma agricultura forte e produtiva para atender aos interesses multilaterais, uma vez que os países desenvolvidos não abririam e a pobreza precisava ser combatida (LEIA, 2009).

Este artigo assume que a participação do Brasil na COP 15 teve grande importância para a política externa ambiental da época, tendo em vista o protagonismo de Lula nas discussões e a proposta dos representantes brasileiros a favor de uma abordagem country driven - cada país orientando suas ações conforme sua realidade local - para o combate à mudança do clima. Esta segunda questão será tratada mais a frente e a primeira será aprofundada agora, de modo a amarrar as ideias da atuação do presidente na arena COP 15, tendo em vista os interesses do Brasil e o contexto institucional em que a discussão ambiental se insere.

Rogowski (1999) oferece algumas reflexões para a compreensão do papel de liderança do chefe do executivo. Reforça-se que a atuação do presidente não pode ser dissociada da rede jogos e de níveis em que ele está imerso - argumento já apresentado a partir de Putnam. Governos que cumprem suas promessas tem muito a ganhar, mas diferentes impulsos domésticos podem fazer com que o líder mude seu posicionamento. Nesse ponto entram as instituições, que podem atuar como constrangimentos em relação à essas mudanças de posicionamento. O ponto é que cabe ao chefe do executivo ter clareza das redes em que se envolve e das consequências de seus

${ }^{10}$ Commodities são produtos de origem primária com pouca industrialização e pouco valor agregado se comparados à produtos industrializados. Alguns exemplos são alimentos como café e trigo, minérios como o cobre, e combustíveis (KRUGMAN, 2015). 
compromissos ou da quebra deles (ROGOWSKI, 1999). O protagonismo de Lula, também abordado pela literatura como o auge da diplomacia presidencial brasileira, ao ser lido por esta perspectiva, leva a constatação de que o executivo, em muitos momentos, conseguiu articular estas questões.

Lula focou em duas agendas em seu discurso na COP 15, a da pobreza e a ambiental. As Figuras 1 e 2 trazem gráficos que mostram a trajetória histórica nacional destas duas questões.

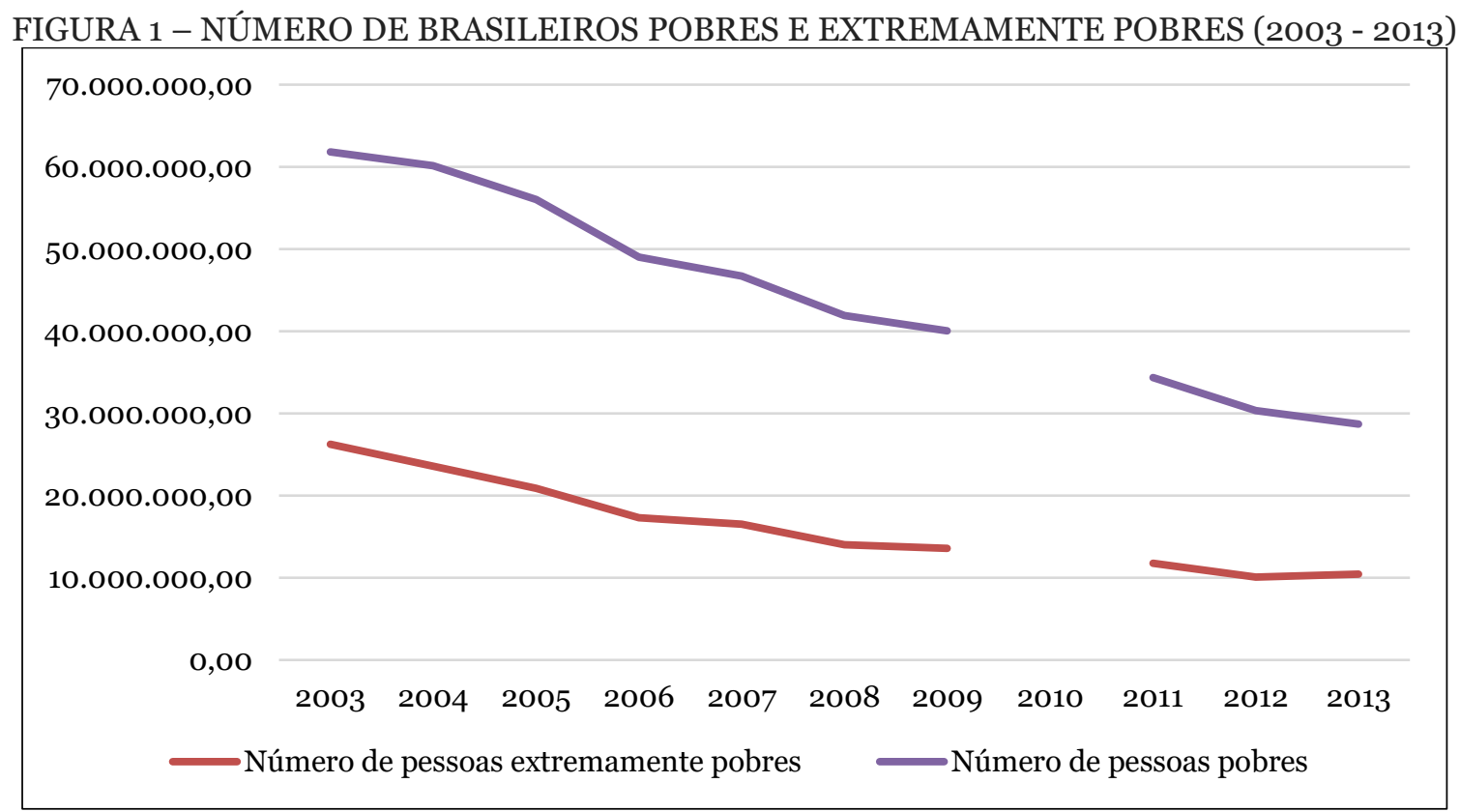

Fonte: elaborado pelo autor a partir de IPEADATA, s/d ${ }^{11}$.

FIGURA 2 - TAXA DE DESMATAMENTO DA AMAZÔNIA LEGAL (1988-2017)

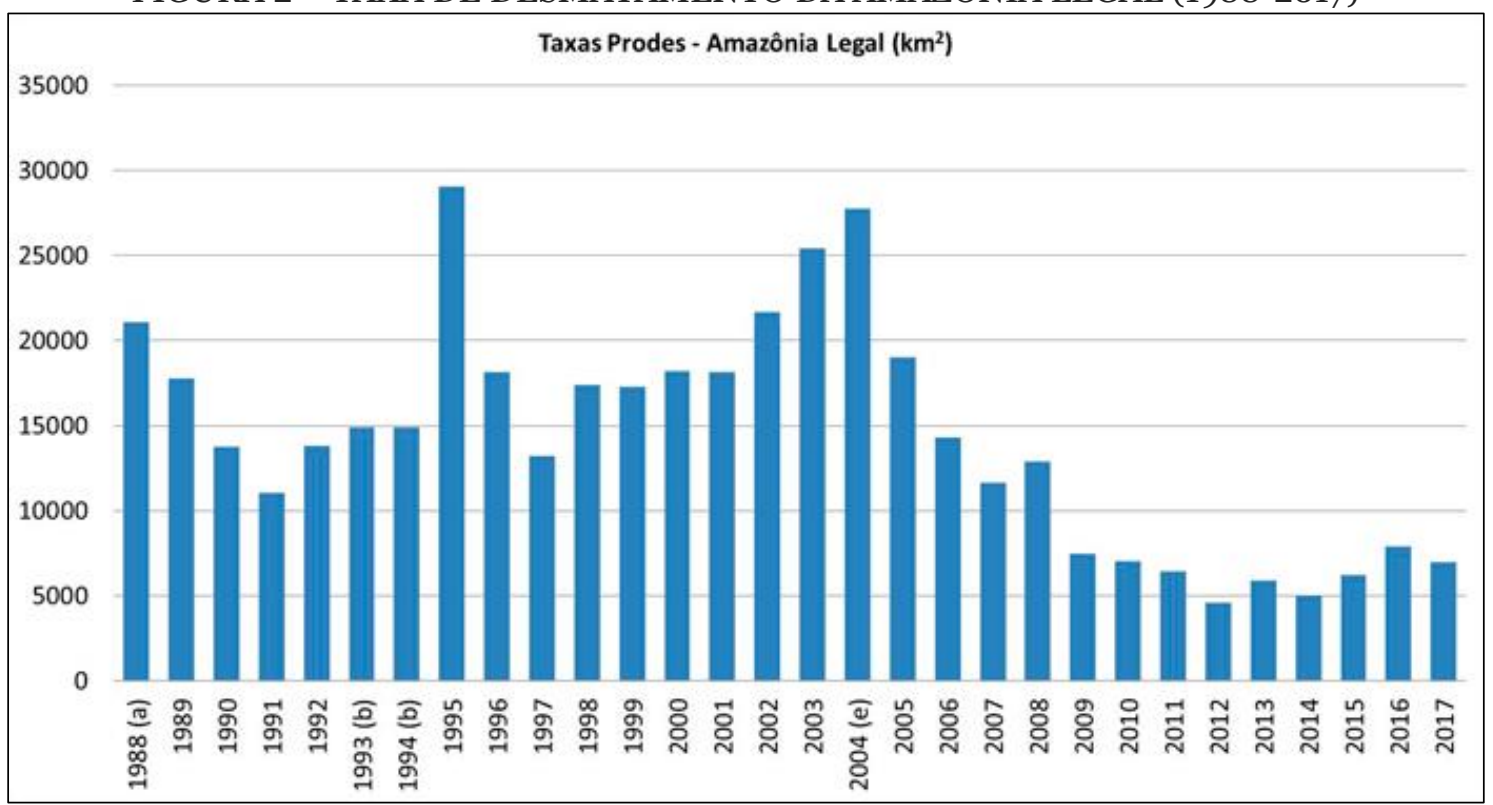

Fonte: INPE, s/d.

${ }^{11} \mathrm{O}$ gráfico foi produzido sem dados de 2010 pois não há dados específicos sobre o ano no IPEADATA ou em outras bases de dados. 
A Figura 1 considera a pobreza e a pobreza extrema ${ }^{12}$, pautas de campanha de Lula e prioritárias em sua agenda doméstica. Como é possível observar, entre 2003 e 2011, a pobreza extrema caiu de 26.242 milhões para 11.772 milhões. Já a pobreza caiu de 61.814 milhões para 34.355 milhões de pessoas (IPEADATA, s/d). Esses dados refletem as ações domésticas do governo Lula de combate à pobreza. Considerando a importância dessa pauta em seus discursos, tal como o da COP 15, verifica-se que, nos anos que se seguiram, ainda que em patamares altos, a taxa continuou a cair, algo que dialoga com a lógica proposta por Rogowski (1999) sobre o poder das instituições, a despeito da troca do líder do executivo.

Sobre a agenda ambiental há que se considerar que o Projeto de Monitoramento do Desmatamento da Amazônia Legal por Satélite (PRODES) monitora esta questão desde 1988. Como se nota na Figura 2, de 2005 até o final do governo Lula, a taxa de desmatamento da Amazônia Legal diminuiu. Um dos motivos foi o lançamento do Plano para Prevenção e Controle do Desmatamento na Amazônia (PPCDAm) em 2004 (INPE, s/d). Observa-se também que essa taxa seguiu caindo durante o governo Dilma, e mesmo com oscilações se manteve em patamares inferiores aos do começo do governo Lula. Isso importa pois, nacionalmente e internacionalmente, é um importante indicador acerca do cumprimento de promessas por parte do executivo, pois, ainda que Lula tenha deixado o cargo, o que se percebe é que as instituições que permaneceram haviam incorporado essa diretriz.

Allison (1971) propõe três modelos de análise de processos políticos que podem ser mobilizados para olhar elementos de uma mesma questão e não são mutuamente excludentes. $\mathrm{O}$ modelo I, da política racional, entende que circunstâncias específicas fazem com que os fenômenos ocorram. As decisões são calculadas de modo premeditado e racional pelos chefes de Estado e tomadores de decisão visando o interesse nacional. O modelo II, do processo organizacional, assume que as decisões passam por uma complexa estrutura de organismos e indivíduos para além dos chefes de Estado. Considera que cada organização responda de uma maneira diferente e a complexidade desse sistema torna-o mais difícil de ser entendido. Já o modelo III, da política burocrática, considera que os tomadores de decisão estão no topo do processo, mas só podendo agir conforme as regras pré-determinadas. Leva-se em conta uma estrutura burocrática e outros líderes no processo de concepção e de ação (ALLISON, 1971).

Em 2009, quando da COP 15, Carlos Minc já substituía Marina Silva. Assim como na época de sua antecessora, tensões entre ONGs ambientalistas e lideranças do PT persistiam. Essas lideranças reivindicavam, dentre outras pautas, aumento de investimentos em usinas hidrelétricas e na construção de estradas (PEREIRA, 2019). Minc era reticente tendo em vista o impacto ambiental que estas obras causariam e como Lula voltava sua atenção, à época, para a imagem internacional do país, muitas de suas decisões tiveram por trás a atuação de Carlos Minc. O modelo

12 Pobreza: "número de pessoas em domicílios com renda domiciliar per capita inferior à linha de pobreza" (IPEADATA, s/d, s/p). Extrema pobreza: "número de pessoas em domicílios com renda domiciliar per capita inferior à linha de extrema pobreza (ou indigência, ou miséria)" (IPEADATA, s/d, s/p). 
I permite observar que, quando Lula discursa na COP e anuncia as reduções voluntárias de emissões de GEE do Brasil (em torno de 36,1\% e 38,9\% até 2020, dado reforçado pela carta enviada pela embaixada de Berlim à UNFCCC), houve um cálculo racional que visou compatibilizar as demandas domésticas com as sugestões do RIMC. O interesse nacional estava refletido nas porcentagens das metas, uma vez que, ao fim de 2009, elas foram aprovadas pelo Congresso Nacional e se tornaram lei, contemplando os interesses de alguns grupos; e também se refletia na imagem internacional, tendo em vista que muitos países, sobretudo aqueles em desenvolvimento, seguiram a orientação apresentada pelo Brasil (ESTEVO, 2011).

Algumas linhas básicas orientaram a política ambiental do governo Lula. O desenvolvimento sustentável era uma proposta, tendo em vista não apenas o aspecto ambiental, mas também o econômico e o social. Incentivava-se a participação social por meio de colaboração qualificada em processos decisórios. Além disso, propunha-se uma gestão das questões ambientais que fosse compartilhada entre as administrações federal, estadual e municipal (KAGEYAMA; SANTOS, 2012). Essas linhas, ao serem analisadas pelo modelo II, indicam que a administração Lula reconhecia a influência de diversos segmentos do país na política ambiental. É evidente que aqui a informação é crucial, conforme apontou em diversos momentos a literatura mobilizada nesse artigo. A compatibilização dos diversos interesses de indivíduos e grupos organizados é um desafio, e isso se torna ainda mais difícil quando se considera o interesse de Lula em contemplar diretrizes internacionais.

O discurso de Lula na COP 15, ao ser analisado pelo modelo III, mostra que o presidente assumia a posição de liderança, mas tinha clareza das regras burocráticas que limitavam sua ação. "No Brasil tem muitos pobres, na África tem muitos pobres, na Índia e na China tem muitos pobres" (LEIA, 2009, s/p), afirmou ele. Essa frase atua em duas direções: Lula reconhece as regras de sua dimensão doméstica, deixando claro que sua principal preocupação é para com a erradicação da pobreza de seu país; e a outra direção é de construção de uma identidade comum para com Índia e China, países dos BRICS e fundamentais para o interesse nacional à época.

Além disso, ainda pela ótica do modelo III, Lula afirma: "as nossas metas não precisam de dinheiro externo. Nós iremos fazer com os nossos recursos, mas estamos dispostos a dar um passo a mais se a gente conseguir resolver o problema que vai atender, primeiro, a manutenção do desenvolvimento dos países em desenvolvimento" (LEIA, 2009, s/p). Há também, nessa fala, duas direções: uma que respeita as regras, reconhecendo que o país possuía, à época, os recursos para reduzir as emissões e ainda assim promover o desenvolvimento; mas também uma atuação de alguém que está no topo, ao ressaltar que os países em desenvolvimento não podem ser privados de solucionarem os problemas mais urgentes em suas realidades domésticas.

Abaixo apresenta-se um fluxograma que sintetiza as análises feitas, tendo em vista os níveis observados na análise e os atores envolvidos nesta rede de jogos. 
FIGURA 3 - FLUXOGRAMA DOS COMPONENTES DOS PROCESSOS DECISÓRIOS DO GOVERNO LULA NA AGENDA AMBIENTAL

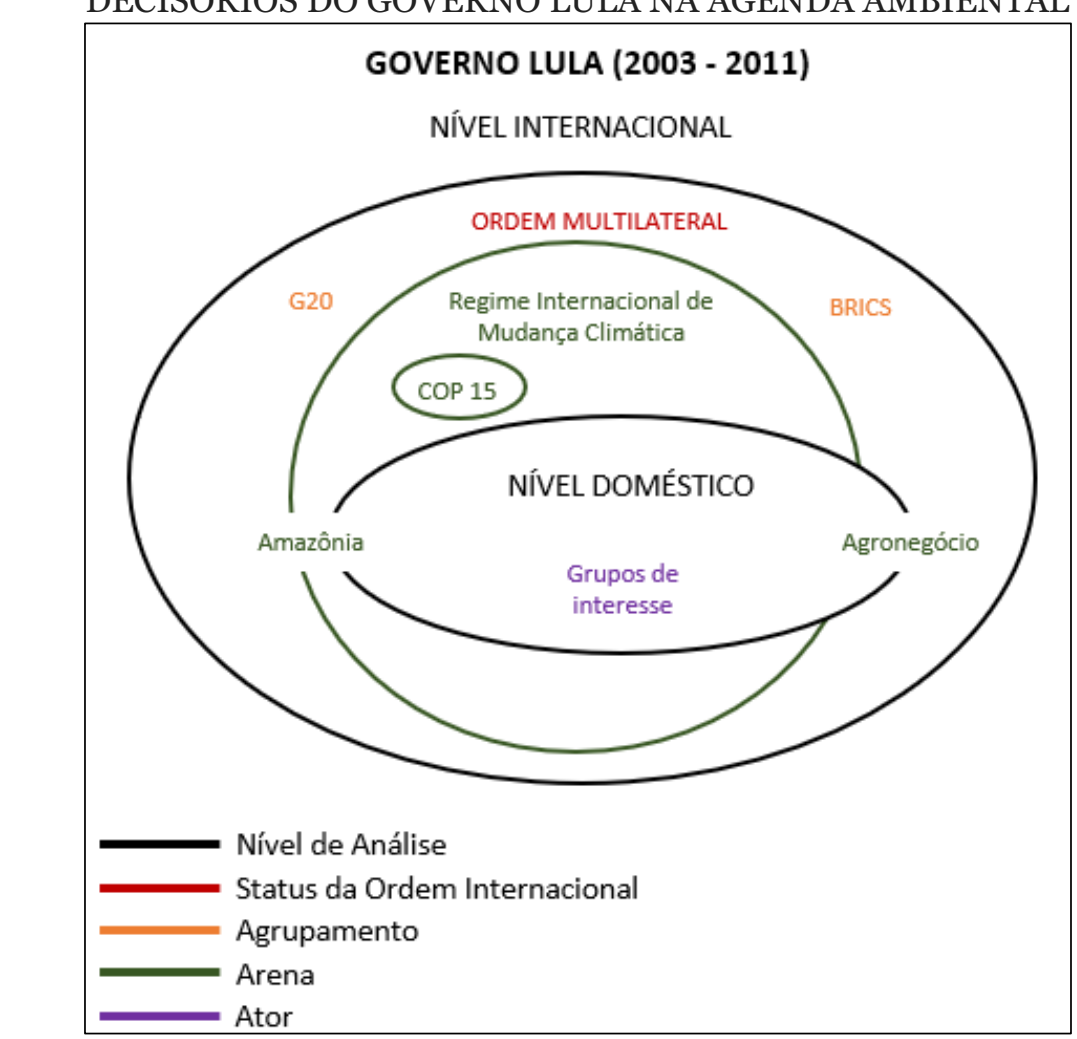

Fonte: elaborado pelo autor a partir da proposta de Karen Mingst (2014) em Princípios de Relações Internacionais.

O fluxograma apresentado na Figura 3 sintetiza as análises feitas nesse artigo, onde focouse nas articulações entre as dimensões domésticas e nacionais para compreender a relação que tiveram com a PEB do governo Lula para a agenda ambiental. Destacou-se a relevância da ordem multilateral à época e como os agrupamentos foram importantes para a projeção brasileira em áreas como a econômica e a ambiental. Ademais, como é possível ver no fluxograma, acredita-se que a arena da Amazônia perpassava os dois níveis, bem como o próprio Regime, e a arena do agronegócio perpassava os dois níveis, tendo em vista os constrangimentos internacionais e as pressões dos diversos grupos domésticos.

\section{CONSIDERAÇÕES FINAIS}

No começo deste artigo afirmou-se que a questão ambiental é um problema de ação coletiva global. Ostrom (2010) afirma que "enquanto muitos dos efeitos da mudança do clima são globais, as causas da mudança do clima são ações tomadas por atores em escalas menores” (OSTROM, 2010, p. 551, versão livre do autor ${ }^{13}$ ). A posição brasileira, apresentada por Lula e por

\footnotetext{
${ }_{13}$ Texto original: "While many of the effects of climate change are global, the causes of climate change are
} the actions taken by actors at smaller scales." 
representantes do país em conferências climáticas da época, indica que o governo estava ciente desta realidade. "O que nós queremos é apenas, conjuntamente, ricos e pobres, estabelecer um ponto comum que nos permita sair daqui" (LEIA, 2009, s/p), afirmou Lula.

Além disso, uma das propostas do governo ia de encontro com essa ideia da responsabilidade de ações em escalas menores e, consequentemente, com a necessidade de combate à mudança do clima também em escalas menores. Em 9 de novembro de 2009, um representante do Brasil na COP 15, junto ao representante da Colômbia, "enfatizou a necessidade de uma abordagem orientada para cada país - country driven" (IISD, 2009, p. 13, versão livre do autor $^{14}$ ). Isso significa que o Brasil identificava que um dos principais desafios de convenções globais sobre o meio ambiente estava em encontrar um consenso que levasse os países presentes a assumirem compromissos robustos e a cumpri-los.

Ostrom (2010) advoga em favor de uma abordagem "policêntrica" para solucionar esta questão. “Policêntrico' conota muitos centros de tomada de decisão que são formalmente independentes uns dos outros" (OSTROM, 2010, p. 552, versão livre do autor ${ }^{15}$ ). Segundo a autora, sistemas policêntricos possuem múltiplas autoridades governamentais em diferentes escalas. Uma das vantagens dessa abordagem é o conhecimento local que se pode utilizar daqueles envolvidos no processo. A ideia, portanto, é que "para resolver a mudança do clima no longo prazo, atividades do dia-a-dia de indivíduos, famílias, firmas, comunidades e governos em múltiplos níveis devem mudar substancialmente (OSTROM, 2010, p. 551, versão livre do autor ${ }^{16}$ )”.

Este artigo mostrou que a política externa ambiental do governo Lula foi orientada por diversas influências domésticas, como lideranças vinculadas ao governo, grupos empresariais do agronegócio e também por ONGs ambientalistas. Além disso, em função do objetivo do governo de alavancar a posição do país em um sistema multilateral, foram tomadas ações, como as metas de redução de emissões, que deram sinais aos outros atores, de que os compromissos do país eram sólidos. Somado à proposta de uma abordagem country driven, que dialoga com a proposta policêntrica de Ostrom (2010), nota-se que havia, por parte do executivo, a noção das potencialidades de uma abordagem que desse autonomia aos níveis estadual e municipal, conforme analisado com o modelo II de Allison.

No entanto, Ostrom (2010) aponta alguns desafios da abordagem policêntrica: a entrada de novos atores e sua não contribuição; e a dificuldade de governança desse sistema (OSTROM, 2010). Isso se reforça tendo em vista outros pontos discutidos nesse artigo, o da informação e o dos desafios da interação entre os níveis domésticos para a concepção da política externa,

\footnotetext{
${ }_{14}$ Texto original: "the need for a country-driven approach."

15 Texto original: "Polycentric1' connotes many centers of decision making that are formally independent of each other."

16 Texto original: "to solve climate change in the long run, the day-to-day activities of individuals, families, firms, communities, and governments at multiple levels must change substantially."
} 
exemplificados aqui por meio dos embates entre grupos de interesses domésticos e os ministros, Marina Silva e Carlos Minc.

Reconhece-se que não foi possível fazer análises profundas e completas sobre as questões apontadas. Escolhas foram feitas de modo a compatibilizar dentro do modelo analítico uma literatura robusta que dialogasse no sentido de permitir um olhar atento sobre a política externa ambiental à época, e também de contemplar o objetivo deste artigo que era o de identificar as interações entre as dimensões doméstica e internacional e como elas influenciaram a PE.

No que tange à política externa dos governos Lula, nota-se seu protagonismo foi elemento chave na agenda ambiental. Sempre se orientando a partir dos interesses do país, como a erradicação da pobreza, desenvolvimento econômico e melhora da posição internacional, Lula atuou de modo a compatibilizar os interesses de grupos domésticos com diretrizes ambientais internacionais, em uma ordem global onde o multilateralismo se expandia e a questão ambiental se tornava mais urgente.

\footnotetext{
*Artigo recebido em 07 de setembro de 2020, aprovado em 10 de dezembro de 2020.
}

\section{REFERÊNCIAS}

ALLISON, G. T. Essence of Decision: Explaining the Cuban Missile Crisis. EUA: Little Brown \& Co., 1971.

CAVALCANTE, Thiago; LIMA, Marcos Costa. A política comercial do governo Lula (2003-2010): uma análise comparativa das relações comerciais do brasil com o Mercosul e com o resto do mundo. Século XXI - Revista de Relações Internacionais, v. 4, n. 2, 2013. Disponível em: http://sumario-periodicos.espm.br/index.php/seculo21/article/view/1867. Acesso em 12 dez. 2020.

CERVO, Amado Luiz. Inserção internacional: a formação dos conceitos brasileiros. São Paulo: Saraiva, 2008.

COP 15/MOP 5 - Copenhague, Dinamarca (dezembro de 2009). PROCLIMA - Programa Estadual de Mudanças Climáticas do Estado de São Paulo. 2020. Disponível em: https://cetesb.sp.gov.br/proclima/conferencia-das-partes-cop/cop-15-mop-5-copenhaguedinamarca-dezembro-de-2009/. Acesso em: 01 dez. 2020.

LEIA na íntegra o discurso de Lula na COP-15. Estadão. 2009. Disponível em: https://sustentabilidade.estadao.com.br/noticias/geral,leia-na-integra-o-discurso-de-lula-na-cop15,484275. Acesso em: 10 dez. 2020.

LOSEKANN, Cristiana. Ambientalistas em movimento no Brasil: entrelaçamentos e tensões entre o Estado e a sociedade durante o governo Lula. Curitiba: Appris, 2014. 
ESTEVO, Jefferson dos Santos. Política externa brasileira para mudanças climáticas. In: $\mathbf{3}^{\mathbf{0}}$ Encontro Nacional ABRI 2011, 3., 2011, São Paulo. Associação Brasileira de Relações Internacionais, Instituto de Relações Internacionais - USP. Disponível em: http://www.proceedings.scielo.br/scielo.php?script=sci arttext\&pid=MSCo00000012201100020 0033\&lng=en\&nrm=abn. Acesso em: $10 \mathrm{dez} .2020$.

G-20. About the G20. 2020. Disponível em: https://www.g20.org/en/il-g20.html. Acesso em: 10 dez. 2020.

IISD. Earth Negotiations Bulletin. $2009-15^{\text {a }}$ Conference of the Parties to the Framework Convention on Climate Change. Disponível em: https://enb.iisd.org/download/pdf/enb12447e.pdf. Acesso em: 10 dez. 2020.

INPE - Coordenação Geral de Observação da Terra. INPE registra 6.947 km2 de desmatamento na Amazônia em 2017. s/d. Disponível em: http://www.obt.inpe.br/OBT/noticias-obt-inpe/inpe-registra-6-947-km2-de-desmatamento-naamazonia-em-2017. Acesso em: 02 dez. 2020.

INPE. Taxa de desmatamento na Amazônia. 2018. Disponível em: http://terrabrasilis.dpi.inpe.br/app/map/deforestation?hl=pt-br. Acesso em: 10 dez. 2020.

IPEADATA. Pobreza: número de pessoas pobres - número de pessoas extremamente pobres. s/d. Disponível em: http://www.ipeadata.gov.br/Default.aspx. Acesso em: 02 dez. 2020.

KAGEYAMA, Paulo Y.; SANTOS, João Dagoberto dos. Aspectos da política ambiental nos governos Lula. Revistafaac, Bauru, v. 1, n. 2, p. 179-192, out. 2011/mar. 2012.

KEOHANE, Robert O.; MILNER, Helen V. Internationalization and Domestic Politics. New York, Cambridge University Press, 1996.

KRUGMAN, Paul R. Economia Internacional. São Paulo: Pearson Education do Brasil, 2015.

MILNER, Helen V. Interests, Institutions, and Information: Domestic Politics and International Relations. Princeton: Princeton University Press, 1997.

MINGST, Karen. Princípios de Relações Internacionais. Rio de Janeiro: Elsevier. $6^{\mathrm{a}}$ edição, 2014.

MOOSMANN, Lorenz; URRUTIA, Cristina; SIEMONS, Anne; CAMES, Martin; SCHNEIDER, Lambert. International Climate Change Negotiations: issues at stake in view of the COP 25 UN Climate Change Conference in Madrid. European Parliament. November, 2019. Disponível em: https://www.europarl.europa.eu/thinktank/en/document.html?reference=IPOL STU(2019)6423 44. Acesso em: o1 dez. 2020.

ONU. Declaração do Rio sobre meio ambiente. 1992. Disponível em: https://cetesb.sp.gov.br/proclima/wp-content/uploads/sites/36/2013/12/declaracao rio ma.pdf. Acesso em: 01 dez. 2020.

OSTROM, Elinor. Institutional Rational Choice: An Assessment of the Institutional Analysis and Development Framework. In: SABATIER, Paul A. Theories of the policy process. Colorado: Westview Press, 2007.

OSTROM, Elinor. Polycentric Systems for Coping with Collective Action and Global Environmental Change. Global Environmental Change, v. 20, n. 4, p. 550-57, 2010. 
PEREIRA, Elson de Menezes. Política Externa Brasileira, governança do clima e cooperação: a importância estratégica e operacional do INPE. Tese (Doutorado - Programa de Doutorado Interinstitucional em Relações Internacionais. Brasília-DF: Universidade de Brasilia, 2019.

PUTNAM, Robert D. Diplomacia e política doméstica: a lógica dos jogos de dois níveis. Revista de Sociologia e Política. Vol.18, No. 36, p. 147-174, 2010.

ROGOWSKI, Ronald. Institutions as Constraints on Strategic Choice”, 1999. In. LAKE, David; POWELL, Robert. Strategic Choice and International Relations. Princeton: Princeton University Press, 1999.

SILVEIRA, Luciana Torrezan; BURNQUIST, Heloisa Lee. Procedimento para análise de decisão quanto à prevenção de doenças em animais: uma aplicação da Teoria dos Jogos. RESR, Piracicaba, SP, vol. 47, $\mathrm{n}^{0}$ 02, p. 435-464, abr/jun, 2009.

TSEBELIS, G. Jogos Ocultos: Escolha Racional no campo da política comparada. São Paulo: Editora da Universidade de São Paulo, 1998.

UNFCCC - United Nations Framework Convention on Climate Change. Communication from the government of Brazil. 2010a. Disponível em: https://unfccc.int/files/meetings/cop 15/copenhagen accord/application/pdf/brazilcphaccord a pp2.pdf. Acesso em: 01 dez. 2020.

UNFCCC - United Nations Framework Convention on Climate Change. Communication from the government of Brazil. 2010b. Disponível em: https://unfccc.int/files/meetings/cop 15/copenhagen accord/application/pdf/brazilcphaccord2 app2.pdf. Acesso em: o1 dez. 2020.

UNFCCC - United Nations Framework Convention on Climate Change. Provisional agenda and annotations. 2009. Disponível em: https://unfccc.int/resource/docs/2009/cop15/eng/o1.pdf. Acesso em: 02 dez. 2020.

VIOLA, Eduardo. O regime internacional de mudança climática e o Brasil. Revista Brasileira de Ciências Sociais, v. 17, n. 50, p. 25-46, out. 2002. 